\title{
Physiologically based pharmacokinetic model for acetone
}

\author{
Shinji Kumagai, Ichiro Matsunaga
}

\begin{abstract}
Objective-This study aimed to develop a physiologically based pharmacokinetic model for acetone and to predict the kinetic behaviour of acetone in the human body with that model.

Methods-The model consists of eight tissue groups in which acetone can be distributed: the mucous layer of the inhaled air tract, the mucous layer of the exhaled air tract, a compartment for gas exchange (alveolus of the lung), a group of blood vessel rich tissues including the brain and heart, a group of tissues including muscles and skin that have low perfusion rates, a group of fatty tissues, an organ for metabolism (liver), and a compartment for urinary excretion (kidney). A mucous layer in the model is only the outermost layer of the mucus lining the wall of the air tract during inhalation and exhalation. To check the relevance of the model, the simulated results were compared with the experimental data. Next, simulation was conducted by changing the volume of the mucous layer and the respiratory rate to clarify the effect of these variables. Finally, simulation of an occupational situation was performed.

Results-With an appropriate value for the volume of mucous layer, the simulated acetone concentrations in arterial blood, end exhaled air, urine, and fatty tissue were found to agree well with the experimental data. The volume of mucous layer and rate of respiration were critical for the appropriate simulation. The simulated occupational situation fitted the observed regression line in field studies quite well. The simulation also enabled predictions to be made about the characteristic kinetics for water soluble solvents.

Conclusion-The model is useful for understanding and explaining the kinetics of acetone.
\end{abstract}

Department of Occupational Health, Osaka Prefectural Institute of Public Health, 1-3-69, Nakamichi, Higashinari-ku, Osaka 537, Japan

S Kumagai

I Matsunaga

Correspondence to: $S$ Kumagai, Department of Occupational Health, Osaka Prefectural Institute of Nakamichi, Higashinari-ku, Osaka, 537 Japan.
(Occup Environ Med 1995;52:344-352)

Keywords: acetone; pharmacokinetic model; absorption

A physiologically based pharmacokinetic model has been developed to simulate uptake, distribution, metabolism, and elimination of an organic solvent. ${ }^{1-8}$ Although such a model requires much information on physiological and biochemical functions, it can be useful for investigating the kinetic behaviour of organic solvents. Several similar models have been used to describe the kinetics in the human body for styrene, ${ }^{23}$ trichloroethylene, ${ }^{4-6}$ tetrachloroethylene, ${ }^{5}$ 2-butoxyethanol, ${ }^{7}$ and n-hexane. ${ }^{8}$

In a physiologically based pharmacokinetic model, the human body is divided into several tissue groups according to the tissue/blood partition coefficient of the organic solvent, the blood flow rate to the tissue, and the metabolic or excretory role. The solvent is assumed to be distributed according to the partition coefficients. Consequently, the ratio between the solvent concentrations in arterial blood and alveolar air should be equal to the blood/air partition coefficient. This assumption was shown to be appropriate for toluene, trichloroethylene, and methylene chloride in experimental studies. ${ }^{9}$ The concentration ratio is, however, much lower than the blood/air partition coefficient for water soluble solvents like acetone and butyl alcohol. ${ }^{9}$ For example, the concentration ratio ranges from 15 to 97 despite the blood/air partition coefficient of 245 for acetone. ${ }^{9}$ Asstrand explained that a water soluble solvent is absorbed in the water of the wet mucous membranes of the respiratory tract and in the saliva during inhalation and then released during exhalation. ${ }^{9}$ Dahl et al showed, in a study of dogs, that the nasal uptake of water soluble solvent increased with an increase in the water/air partition coefficient. ${ }^{10}$ Consequently, the mucus layer of the respiratory tract plays an important part in the kinetics of water soluble solvents.

Gerde $e t a l^{11}$ and Morris et al ${ }^{12}$ developed physiologically based pharmacokinetic models for the nasal uptake of organic solvents. Johanson constructed a similar model for simulating the uptake of solvent in the wall of the air tract. ${ }^{13}$ In his physiologically based pharmacokinetic model, the lung was divided into 18 compartments and the breathing was treated as a cyclic process. Johanson showed that the simulated and the experimentally observed concentrations in the exhaled air agreed. In our paper, we propose a simple model that can describe the kinetic behaviour of acetone in the human body taking into account the uptake in the mucous layer of the respiratory tract.

\section{Methods}

DESCRIPTION OF THE MODEL

The body is considered to consist of eight tissue groups in which acetone can be 
Figure 1 Diagram of a physiologically based pharmacokinetic model for acetone. $B W=$ body weight; $V_{X}=$ volume of tissue group $X$;

$V A T=$ volume of mucous layer of air tract; $C_{X}=$ acetone concentration in tissue group $X ; C_{\text {exp }}=$ acetone exposure concentration

$C_{\text {in }}=$ acetone

concentration in air inhaled into alveolus; $C_{\text {out }}=$ acetone

concentration in air exhaled from alveolus; $C_{\text {out end }}=$ acetone concentration in end exhaled air;

$\lambda_{x}=$ tissue/blood partition coefficient in tissue group $X ; \lambda_{B}=$ bloodlair partition coefficient; $\lambda_{w}=$ waterlair partition coefficient;

$\lambda_{U}=$ urine/air partition coefficient;

$A v=$ alveolar ventilation;

$R R=$ respiratory rate;

$Q_{\text {tot }}=$ cardiac output;

$Q_{x}=$ blood flow rate to

tissue group $X$;

$L=$ alveolus of lung;

$R=$ blood vessel rich

tissues; $M=$ muscle and

skin; $F$ = fatty tissues;

$H=$ liver; $K=$ kidney;

$Q_{U}=$ output of urine;

$V \max =$ maximum

enzymatic reaction rate;

$\mathrm{Km}=$ Michaelis constant

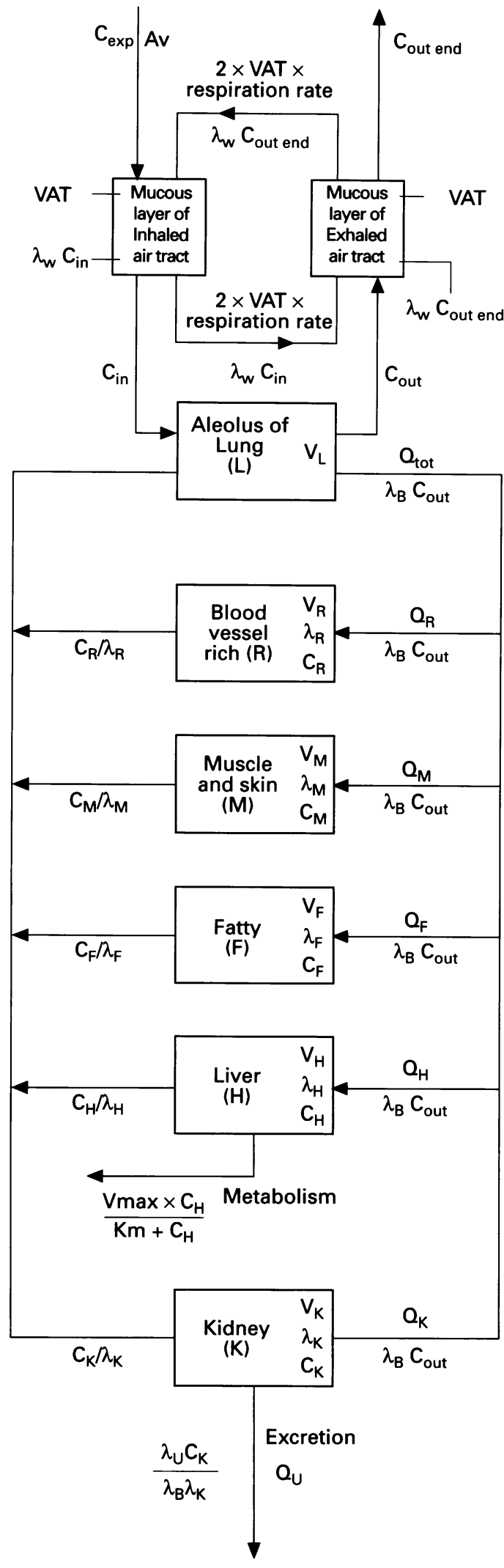

distributed (fig 1): the mucous layer of the inhaled air tract, the mucous layer of the exhaled air tract, a compartment for gas exchange (alveolus of the lung), a group of blood vessel rich tissues including the brain and heart, a group of tissues including muscles and skin that have low perfusion rates, a group of fatty tissues, an organ for metabolism (liver) and a compartment for urinary excretion (kidney).
Table 1 Volumes of tissue groups and tissue/blood partition coefficients (2) of acetone

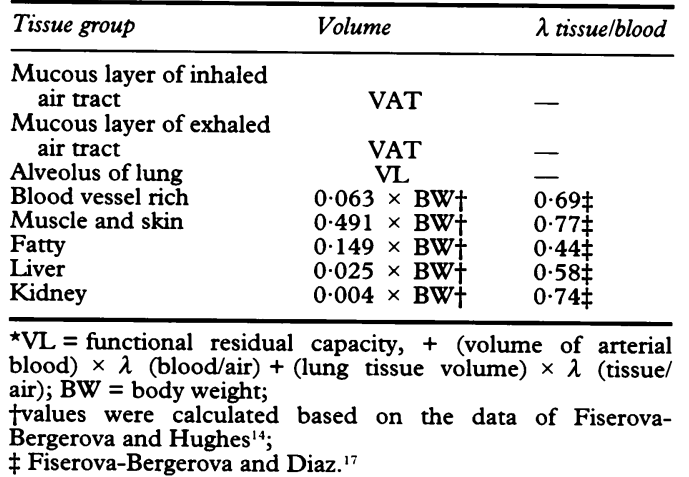

The mucous layer of the inhaled and exhaled air tracts correspond to the outermost layer of the mucus lining the wall of the air tracts during inhalation and exhalation respectively. The outer mucous layer was assumed to be 1-5 $\mu \mathrm{m}$ thick. The total area of the mucous layer of the air tract (from nose to terminal bronchioles) is about $5000 \mathrm{~cm}^{2} .^{13}$ The volume of each compartment is from 0.5 to $2.5 \mathrm{ml}$. The volume of the lung was calculated according to Fiserova-Bergerova (table 1). ${ }^{1}$ For the other five tissue groups, each volume was determined by multiplying the body weight by the relative percentage of the tissue group (table 1). The relative percentage values were calculated with the equations described by Fiserova-Bergerova et al. ${ }^{14}$

The blood/air, water/air, and urine/air partition coefficients for acetone are 245, 395, and 325, respectively, as shown by Sato and Nakajima $^{15}$ and Wigaeus et al. ${ }^{16}$ The partition coefficient for mucous layer/air was assumed to be the same as that for water/air. For the other five tissue groups, the tissue/blood partition coefficients for acetone have been reported by Fiserova-Bergerova and Diaz (table 1). ${ }^{17}$

Alveolar ventilation and cardiac output at rest were taken from the data of Adolph ${ }^{18}$ and Stahl ${ }^{19}$ respectively (table 2 ). Alveolar ventilation and cardiac output at a physical workload of $50 \mathrm{~W}$ were assumed to be 3.0 and 1.8 times those at rest, respectively, on the basis of linear relations between these physiological functions and workload as shown by Åstrand. ${ }^{9}$

The blood flow to each tissue group was determined by multiplying the cardiac output by the relative percentage of flow to each tissue (table 2). The relative percentage values at rest and at $50 \mathrm{~W}$ were calculated based on the data shown by Fiserova-Bergerova et al ${ }^{14}$ and by Åstrand ${ }^{9}$ respectively.

When air containing acetone is inhaled through the air tract, acetone is partly taken up in the mucous layer of the tract. The acetone concentration in the tract is assumed to be at equilibrium with that in the inhaled air that leaves the tract and reaches the entrance of the alveolus. The acetone concentration in the air that enters the alveolus (if the mucous layer is negligible) is equal to the exposure concentration. When alveolar air is exhaled through the air tract, acetone in the mucous layer of the exhaled air tract is partly released. 
Table 2 Alveolar ventilation (v) and cardiac output (Q) at rest and during working hours

\begin{tabular}{|c|c|c|}
\hline & $\begin{array}{l}\text { Rest } \\
(O W)\end{array}$ & $\begin{array}{l}\text { Working hours } \\
(50 W)\end{array}$ \\
\hline $\begin{array}{l}\text { Alveolar ventilation }(1 / \mathrm{min}) \\
\text { Cardiac output }(1 / \mathrm{min}) \\
\text { Blood vessel rich } \\
\text { Muscle and skin } \\
\text { Fatty } \\
\text { Liver } \\
\text { Kidney } \\
\text { Output of urine }(1 / \mathrm{min})\end{array}$ & $\begin{array}{l}\mathrm{V}(0)=0.7 \times 0.332 \times \mathrm{BW}^{0.74 \star} \\
\mathrm{Q}(0)=0.187 \times \mathrm{BW}^{0.81} \dagger \\
0.30 \times \mathrm{Q}(0) \ddagger \\
0.21 \times \mathrm{Q}(0) \ddagger \\
0.05 \times \mathrm{Q}(0) \ddagger \\
0.24 \times \mathrm{Q}(0) \ddagger \\
0.20 \times \mathrm{Q}(0) \ddagger \\
\mathrm{QU}=3.08 \times 10^{-5} \times\end{array}$ & $\begin{array}{l}\mathrm{V}(50)=3.0 \times \mathrm{V}(0) \oint \\
\mathrm{Q}(50)=1.8 \times \mathrm{Q}(0) \oint \\
0.19 \times \mathrm{Q}(50) \ddagger \\
0.50 \times \mathrm{Q}(50) \ddagger \\
0.07 \times \mathrm{Q}(50) \ddagger \\
0.13 \times \mathrm{Q}(50) \ddagger \\
0.11 \times \mathrm{Q}(50) \ddagger \\
W^{0.82 \star}\end{array}$ \\
\hline
\end{tabular}

$\star$ Adolph ${ }^{18} ;$ † Stahl $;{ }^{19} \ddagger$ values were calculated from the data of Astrand, ${ }^{9}$ and FiserovaBergerova; ${ }^{14} \delta$ values were calculated from the linear relations between these physical functions and workload as shown by Åstrand. ${ }^{9}$
The acetone concentration in the mucous layer of the exhaled air tract is also assumed to be at equilibrium to that in the exhaled air that leaves the tract and exits from the nose or mouth. The air exhaled from the nose or mouth in our model always relates to the value of the end exhaled air, because the respiratory dead space is ignored. Thus, this air is called end exhaled air in this paper. The air exhaled from the alveolus to the air tract is called exhaled alveolar air. Usually in examinations, the acetone concentration in the exhaled alveolar air is assumed to be equal to that in the end exhaled air, but those concentrations are clearly distinguished from each other in our model. If the mucous layer is negligible, these two concentrations are the same.

The wall of the air tract is lined with a mucous layer 5-10 $\mu \mathrm{m}$ thick. ${ }^{13}$ Although our model includes the outermost layer $(1-5 \mu \mathrm{m})$ of the mucus as the inhaled and exhaled air tract, the deeper mucous layer and the wall tissue are not taken into account. This is the reason why the instantaneous equilibrium of acetone between the deeper portion of the mucous layer and air may not be achieved due to the rapid and cyclic variation of the acetone concentration caused by cyclic breathing.

In our model, alveolar ventilation is treated as a continuous process. In reality, however, it is a cyclic process of inhalation and exhalation. Accordingly, the mucous layer of the inhaled air tract at the end of inhalation corresponds to that of the exhaled air tract at the start of exhalation and vice versa. Consequently, the mucus in one tract can be hypothetically considered to be exchanged for the other at twice the respiratory rate. Thus the mucus in the tracts can be assumed to circulate between these compartments at the flow rate of $2 \times$ volume of the mucous layer $\times$ respiration rate (fig 1 ). Although this circulation is an intermittent process, it is described as a continuous process in our model. Respiration rate was selected to be $14 \mathrm{~min}^{-1}$ at rest and $18 \mathrm{~min}^{-1}$ for a workload of $50 \mathrm{~W} .{ }^{1320}$

Acetone is metabolised to acetic acid, formic acid, and carbon dioxide in animals and humans. ${ }^{21} 22$ The organ for metabolism of acetone was assumed to be only the liver in our model. Hallier et al, in a rat study on acetone, reported the Michaelis constant $(\mathrm{Km})$ to be $160 \mathrm{ppm}$ in the atmosphere and the maximum enzymatic reaction rate to be 18.6 $\mathrm{mg} / \mathrm{h} / \mathrm{kg}$ of body weight. ${ }^{21}$ The $\mathrm{Km}$ value corresponds to $83.5 \mathrm{mg} / 1$ in the animal body because the animal/air partition coefficient has been reported to be $220 .{ }^{21}$ In this paper, the $\mathrm{Km}$ value in humans was assumed to be the same. Because the liver/blood partition coefficient is $0.58,{ }^{17}$ the $\mathrm{Km}$ value in liver was calculated to be $48.4 \mathrm{mg} / 1$. The maximum enzymatic reaction rate was determined based on the assumption that it is linearly related to the 0.75 power of body weight.

Acetone is assumed to be directly excreted by the kidneys at a rate proportional to the urine/blood partition coefficient. The output of urine was calculated with the equation reported by Adolph. ${ }^{18}$

\section{COMPUTER SIMULATION}

The simultaneous differential equations that describe the kinetic behaviour of acetone are as follows (see fig 1 for abbreviations):

inhaled air tract:

$$
\begin{gathered}
\text { VAT. } \lambda_{w}\left(d C_{i n} / d t\right)=A v \cdot C_{\text {exp }}+ \\
\text { 2.VAT.RR. } \lambda_{w} \cdot C_{\text {out end }}-A v \cdot C_{\text {in }}- \\
\text { 2.VAT.RR. } \lambda_{w} \cdot C_{\text {in }}
\end{gathered}
$$

exhaled air tract:

$$
\begin{gathered}
\text { VAT. } \lambda_{w}\left(\mathrm{dC}_{\text {out end }} / \mathrm{dt}\right)=\mathrm{Av} \cdot \mathrm{C}_{\text {out }}+ \\
\text { 2.VAT.RR. } \lambda_{\mathrm{w}} \cdot \mathrm{C}_{\text {in }}-\mathrm{Av} \cdot \mathrm{C}_{\text {out end }}- \\
\text { 2.VAT.RR. } \lambda_{w} \cdot \mathrm{C}_{\text {out end }}
\end{gathered}
$$

lung alveolus

$$
\begin{gathered}
\mathrm{V}_{\mathrm{A}}\left(\mathrm{dC} \mathrm{C}_{\text {out }} / \mathrm{dt}\right)=\mathrm{Av} \cdot \mathrm{C}_{\mathrm{in}}+\mathrm{Q}_{\mathrm{R}} \cdot \mathrm{C}_{\mathrm{R}} / \lambda_{\mathrm{R}}+\mathrm{Q}_{\mathrm{M}} \cdot \mathrm{C}_{\mathrm{M}} / \lambda_{\mathrm{M}} \\
+\mathrm{Q}_{\mathrm{F}} \cdot \mathrm{C}_{\mathrm{F}} / \lambda_{\mathrm{F}}+\mathrm{Q}_{\mathrm{H}} \cdot \mathrm{C}_{\mathrm{H}} / \lambda_{\mathrm{H}}+\mathrm{Q}_{\mathrm{K}} \cdot \mathrm{C}_{\mathrm{K}} / \lambda_{\mathrm{K}}- \\
\mathrm{Q}_{\text {tot }} \cdot \lambda_{\mathrm{B}} \cdot \mathrm{C}_{\text {out }}-\mathrm{Av} \cdot \mathrm{C}_{\text {out }}
\end{gathered}
$$

Liver:

$$
\begin{gathered}
\mathrm{V}_{\mathrm{H}}\left(\mathrm{dC}_{\mathrm{H}} / \mathrm{dt}\right)=\mathrm{Q}_{\mathrm{H}} \cdot \lambda_{\mathrm{B}} \cdot \mathrm{C}_{\text {out }}-\mathrm{Q}_{\mathrm{H}} \cdot \mathrm{C}_{\mathrm{H}} / \lambda_{\mathrm{H}}- \\
\operatorname{Vmax} \cdot \mathrm{C}_{\mathrm{H}} /\left(\mathrm{Km}+\mathrm{C}_{\mathrm{H}}\right)
\end{gathered}
$$

Kidney:

$$
\begin{gathered}
\mathrm{V}_{\mathrm{k}}\left(\mathrm{dC} \mathrm{C}_{\mathrm{K}} / \mathrm{dt}\right)=\mathrm{Q}_{\mathrm{K}} \cdot \lambda_{\mathrm{B}} \cdot \mathrm{C}_{\text {out }}-\mathrm{Q}_{\mathrm{k}} \cdot \mathrm{C}_{\mathrm{K}} / \lambda_{\mathrm{K}}- \\
\mathrm{Q}_{\mathrm{U}} \cdot \lambda_{\mathrm{U}} \cdot \mathrm{C}_{\mathrm{K}} / \lambda_{\mathrm{B}} \cdot / \lambda_{\mathrm{K}}
\end{gathered}
$$

blood vessel rich tissues:

$$
\mathrm{V}_{\mathrm{R}}\left(\mathrm{dC} \mathrm{C}_{\mathrm{R}} / \mathrm{dt}\right)=\mathrm{Q}_{\mathrm{R}} \cdot \lambda_{\mathrm{B}} \cdot \mathrm{C}_{\text {out }}-\mathrm{Q}_{\mathrm{R}} \cdot \mathrm{C}_{\mathrm{R}} / \lambda_{\mathrm{R}}
$$

Equations for muscle and skin and fatty groups are similar to that for the blood vessel rich group.

The differential equations were solved by the Runge-Kutta-Gill method with a software package developed by Yamaoka. ${ }^{23}$ Body weight was set at $70 \mathrm{~kg}$ for a standard male. As the endogenous acetone concentration in blood was reported to be $1.3 \mathrm{mg} / 1$ by Wigaeus et $a l,{ }^{16}$ this value was added to the simulated acetone concentration in blood.

\section{Results}

\section{COMPARISON WITH EXPERIMENTAL DATA}

Experimental studies with human volunteers exposed to acetone have been reported by Wigaeus et al. ${ }^{1624}$ To check the relevance of our model, simulations of the exposure scenarios were performed.

\section{Exposure at rest (series 1)}

Acetone concentration in arterial blood, end exhaled air, and urine were simulated based on exposure to $1309 \mathrm{mg} / \mathrm{m}^{3}$ (552 ppm) at rest 
Figure 2 Comparison between simulated results and observed data (Wigaeus et al. ${ }^{16}$ ) of acetone concentrations in arterial blood and end exhaled air during exposure.

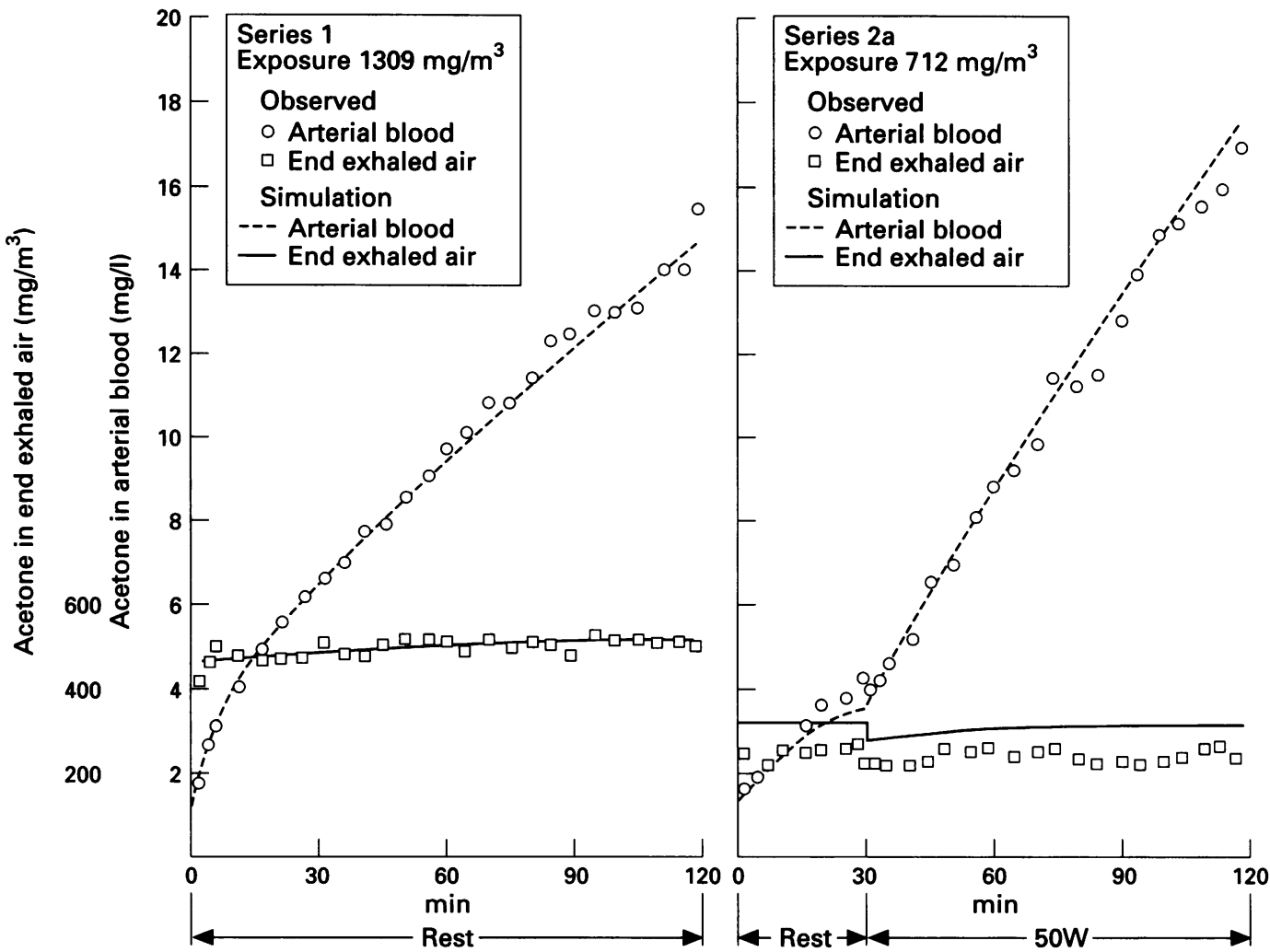

for two hours, which is the exposure scenario of "series 1" reported by Wigaeus et al. ${ }^{16}$ Figures 2 and 3 show the simulated results with the volume of mucous layer being $0.6 \mathrm{ml}$. There is good agreement between the simulated and experimentally observed values.

Exposure at rest and at $50 \mathrm{~W}$ (series $2 a$ ) Simulation was performed based on the exposure to $712 \mathrm{mg} / \mathrm{m}^{3}(300 \mathrm{ppm})$ at rest (30 $\left.\mathrm{min}\right)$
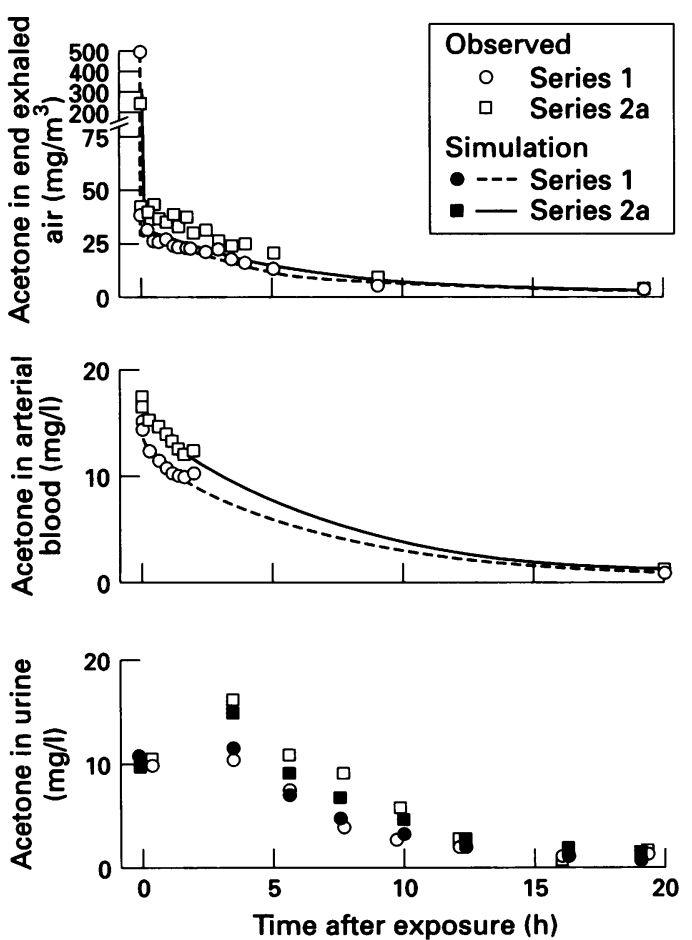

and at $50 \mathrm{~W}$ (90 min), which is the scenario of "series $2 a$ ". ${ }^{16}$ Figures 2 and 3 also present the results for series $2 \mathrm{a}$. The simulated curves were obtained when the volume of the mucous layer was $2 \cdot 0 \mathrm{ml}$. Although the simulated concentration of acetone in end exhaled air was about $20 \%$ more than that observed during exposure and about $20 \%$ less after exposure, the simulated blood and urine concentrations of acetone agreed well with the corresponding observed values. Thus the simulation is considered to be tolerably appropriate.

Exposure at $50 \mathrm{~W}$ (series 3)

Wigaeus et al reported acetone concentrations in arterial blood and subcutaneous adipose tissue in an experiment with exposure to 1240 $\mathrm{mg} / \mathrm{m}^{3}$ (523 ppm) at $50 \mathrm{~W}$ for two hours. ${ }^{24} \mathrm{In}$ the simulation of this exposure scenario, when the volume of the mucous layer was $1.0 \mathrm{ml}$, the simulated concentration of acetone in the blood at the end of exposure was $38.2 \mathrm{mg} / \mathrm{l}$, which is nearly equal to the observed value of $37.6 \mathrm{mg} /$. The acetone concentrations in subcutaneous adipose tissue at 30 and 90 minutes after the exposure were reported to be $13 \cdot 1$ and $13.5 \mathrm{mg} / \mathrm{kg}$, respectively. The corresponding simulated acetone concentrations in fatty tissues were 14.6 and $12.6 \mathrm{mg} / \mathrm{l}$ respectively, which agreed well with the observed values.

These three simulations show that our model can describe the kinetics of acetone in the human body with an appropriate value for the volume of the mucous layer.

EFFECT OF VOLUME OF MUCOUS LAYER OF AIR TRACT AND RESPIRATION RATE

The volume of the mucous layer and respiration rate were changed to simulate the 
concentrations of acetone in the blood and end exhaled air in series 1 . Figure 4 shows these simulated concentrations at the end of exposure. The concentration of acetone in the blood decreases and that in end exhaled air increases with increasing volumes of mucous layer. Respiration rate acts similarly. If the

Figure 4 Effects of volume of mucous layer and respiration rate on acetone concentrations in arterial blood and end exhaled air. (Simulated values at the end of exposure in series 1.)

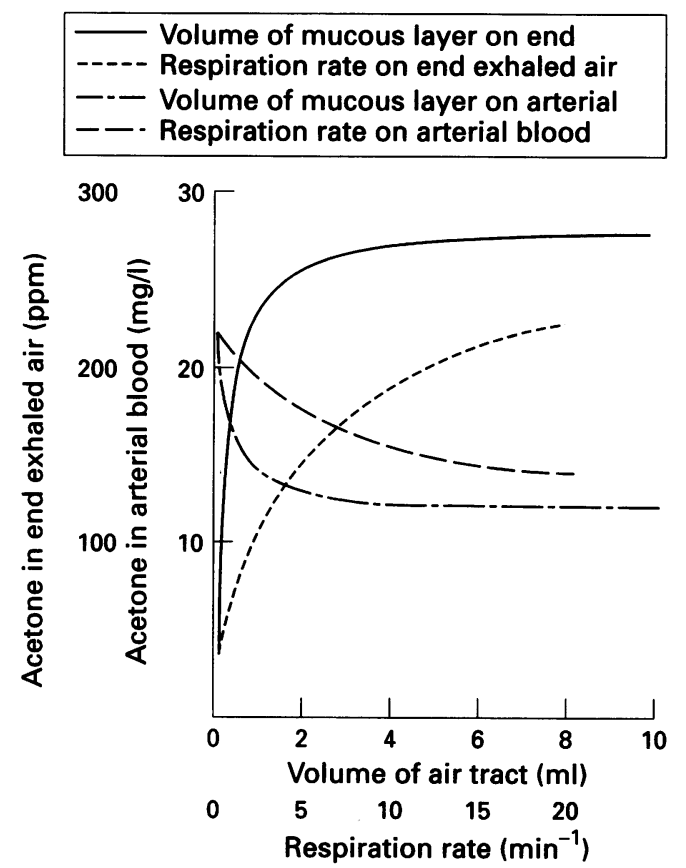
was performed based on the
Figure 5 Time courses of acetone concentrations in arterial blood and tissue groups. The simulation exposure at $750 \mathrm{ppm}$ during working hours ( $0-3$ $h, 4-8 h$ ) and at $0 \mathrm{ppm}$ during noon recess $(3-4 h)$ and after working hours $(8-24 h)$. The physical workload was assumed to be $50 \mathrm{~W}$ during working hours and $0 \mathrm{~W}$ during noon recess and after working hours.

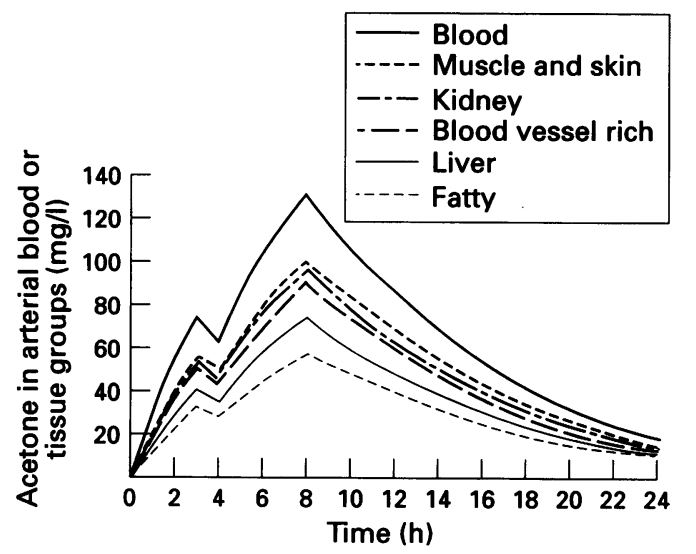

Figure 6 Time courses of acetone concentrations in air. Exposure scenario is the same as that in fig 5 . Abbreviations as for fig 1 .

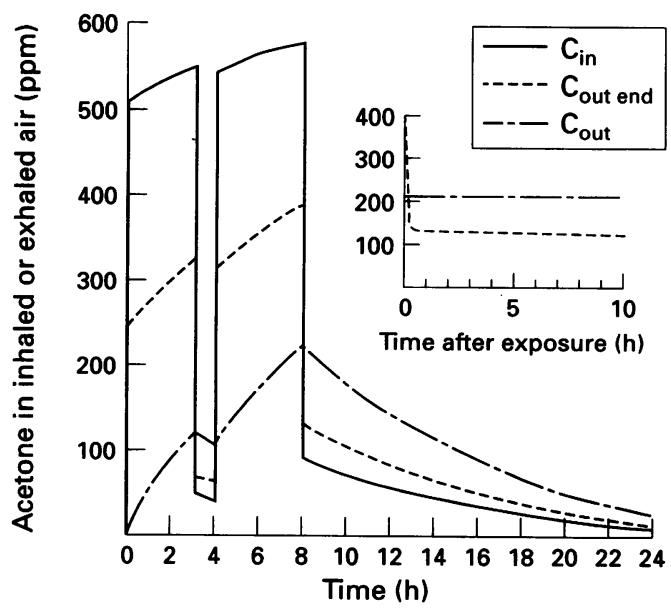

volume of the mucous layer or respiration rate is zero, the simulated concentration of acetone in the blood should be about 1.5 times as much as the corresponding observed value (observed value $=14.8 \mathrm{mg} / 1 \quad v$ simulated result $=21.9 \mathrm{mg} / \mathrm{l}$ ) and the simulated concentration of acetone in end exhaled air should be one sixth (observed value $=212 \mathrm{ppm} v$ simulated result $=36 \mathrm{ppm}$ ). Thus, these variables are critical for the appropriate simulation.

\section{SIMULATION OF OCCUPATIONAL EXPOSURE}

The simulations were performed based on exposures from 10 to $2000 \mathrm{ppm}$ during working hours (three hours in the morning and four hours in the afternoon) and at $0 \mathrm{ppm}$ during the noon recess (one hour) and after working hours (16 hours). The physical workload was assumed to be $50 \mathrm{~W}$ during working hours and $0 \mathrm{~W}$ during the noon recess and after working hours. A volume for the mucous layer of $1.0 \mathrm{ml}$ was selected.

\section{Time course of acetone concentration in the human body}

Figure 5 shows the simulated acetone concentration in each tissue group at an exposure of $750 \mathrm{ppm}$, which is the threshold limit value recommended by the American Conference of Governmental Industrial Hygienists. ${ }^{25}$ The concentration of acetone in the blood increases continuously during exposure and decreases after exposure. The time courses of acetone concentrations in muscle and skin, blood vessel rich tissues, kidney, liver, and fatty tissues are similar to that in the blood. The ratio between acetone concentrations in each tissue group and arterial blood is nearly equal to the tissue/blood partition coefficient at any time. This simulated result predicts that the acetone concentration in each tissue group rapidly reaches equilibrium throughout the whole body.

Figure 6 shows the simulated acetone concentrations in inhaled and exhaled air. Although the concentration in exhaled alveolar air continuously increases in proportion to the concentration in the blood (fig 5) according to our assumption, concentrations in inhaled and end exhaled air very rapidly rise to $510 \mathrm{ppm}$ and $240 \mathrm{ppm}$ respectively at the start of exposure. Thereafter, these values increase continuously in parallel during exposure and rapidly decrease after exposure. Concentrations of acetone in inhaled air of 510 to $580 \mathrm{ppm}$ are lower than the exposure concentration (750 ppm). Consequently, this simulation predicts that about $25 \%$ of the inhaled acetone is absorbed in the mucous layer of the air tract. The difference between acetone concentrations in exhaled alveolar and end exhaled air is from 160 to $240 \mathrm{ppm}$, which is nearly equal to the difference between inhaled and exposed air. Thus, this simulated result suggests that most of the acetone absorbed in the mucous layer during inhalation is released in the exhaled air during exhalation. After the exposure, the acetone concentration is higher in exhaled alveolar air than end exhaled air. The difference between 


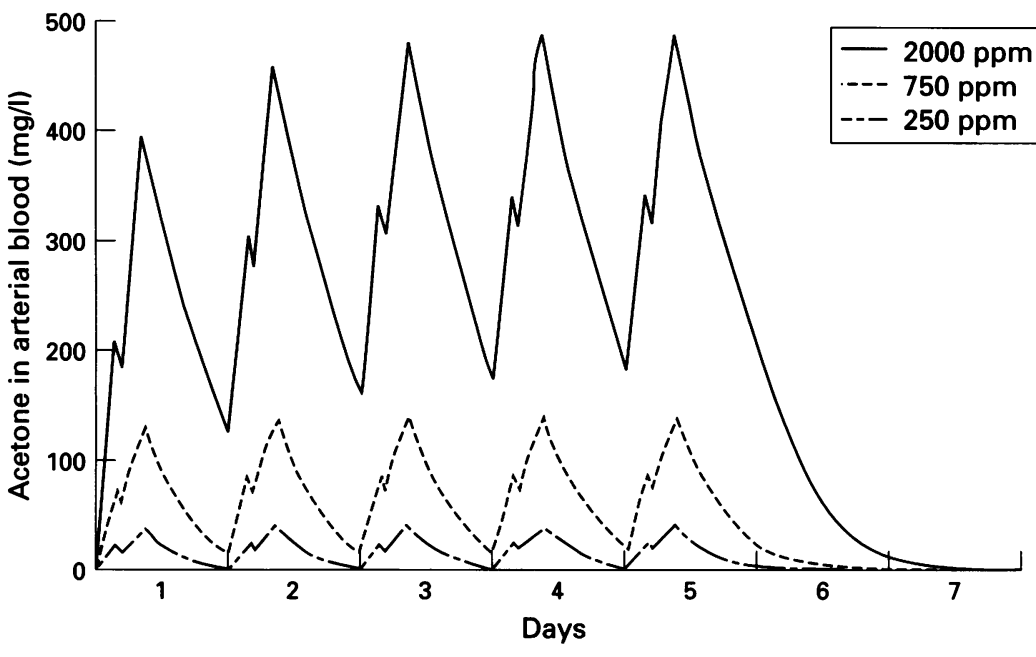

Figure 7 Time courses of acetone concentrations in arterial blood during one week. The physical workload is the same as that of fig 6.

these two concentrations is nearly equal to the acetone concentration in inhaled air. Accordingly, the simulation predicts that acetone in the exhaled alveolar air is partly absorbed in the mucus layer during exhalation and the absorbed acetone returns to the alveoli again during inhalation.

Figure 7 presents the simulated time course of concentrations of acetone in the blood over one week. At exposure to $250 \mathrm{ppm}$, there is nearly no acetone in the blood before the shift on any day. At exposure to $750 \mathrm{ppm}$, there is a burden of acetone in the blood before the shift on the second day and the burden before the shift becomes constant after the second day. But the concentration of acetone in the blood nearly returns to zero after two days holiday. The simulation at $2000 \mathrm{ppm}$ predicts a large burden of acetone in the blood before the shift on the second day. The burden before the shift becomes constant on the fourth and fifth days, but returns to normal after two days holiday. The simulated acetone concentrations in the other tissue groups are parallel to those in the blood, although the results are not shown in the figure. Consequently, long term accumulation of acetone in the body is not expected.

\section{Biological exposure indices}

The acetone concentration in venous blood which leaves the muscles and skin can be equal to the acetone concentration in venous blood collected from the arm. Figure 8 shows the simulated relation between this value and exposure at the end of the exposure. Although the simulated line is slightly curved due to metabolic saturation, the concentration of acetone in the blood at the end of exposure can be a good biological exposure index.

Figure 9 presents the concentrations of acetone in exhaled alveolar air and end exhaled air at the end of exposure and at one minute after exposure. Although all simulated lines show slight curves, the curvatures are not large. Consequently, these values may be biological exposure indices. The ratios of the

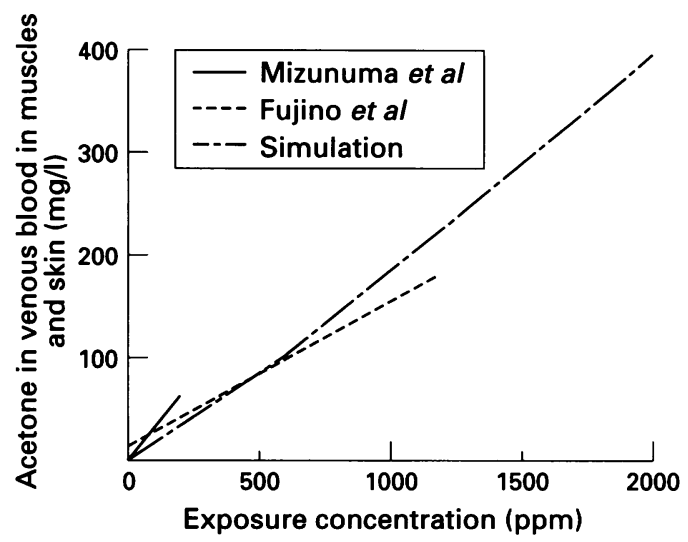

Figure 8 Simulated relation between exposure concentration and acetone concentration in venous blood in muscle and skin at the end of exposure, and observed regression lines in field studies by Fujino et al ${ }^{29}$ and Mizunuma et al. ${ }^{30}$

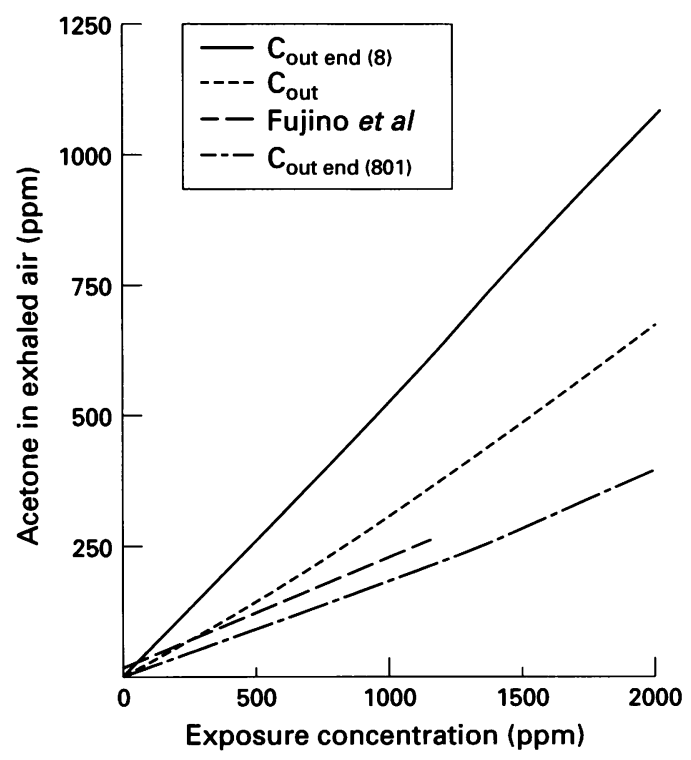

Figure 9 Simulated relations between exposure concentration and acetone concentrations in exhaled air, and observed regression line in field study by Fujino et al. ${ }^{29}$ $\mathrm{C}_{\text {out }}$ is acetone concentration in air exhaled from the alveoli of the lungs at the end of exposure. $C_{\text {out end(8) }}$ and $C_{\text {out end(801) }}$ are acetone concentrations in end exhaled air at the end of exposure and that at 1 min after exposure, respectively.

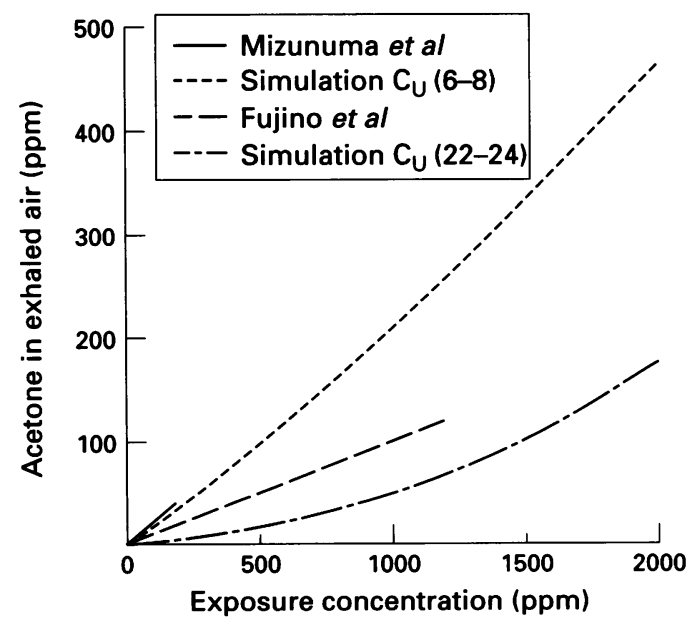

Figure 10 Simulated relations between exposure concentration and acetone concentrations in urine, and observed regression lines in field studies by Fujino et al ${ }^{29}$ and Mizunuma et al. ${ }^{30} C_{U}(6-8)$ and $C_{U}(22-24)$ are acetone concentrations in the urine accumulated in the bladder during the last $2 h$ of exposure and that during $2 h$ before the next shift, respectively. 
acetone concentrations of end exhaled air at the end of exposure and one minute after are 2.7 to 3.5 in spite of the short interval (one minute) between the two collection times. Figure 6 shows that although the value of end exhaled air at the end of exposure changes rapidly for the first minute after exposure, after this that variable stabilises. Thus the concentration of acetone in end exhaled air one minute after the end of exposure is expected to be a good biological exposure index. The concentration of acetone in exhaled alveolar air almost never changes within 10 minutes after exposure (fig 6), and thus can be considered to be a good biological exposure index.

Figure 10 shows the simulated acetone concentration in urine accumulated in the bladder during the last two hours of exposure and during the last two hours before the next shift. As the simulated urinary curve for the last two hours of exposure is nearly linearly related to exposure, this urinary concentration is expected to be a biological exposure index. There is almost no acetone in the urine in the last two hours before the next shift for exposures of $300 \mathrm{ppm}$ or less, but it increases considerably for exposures of more than 300 ppm. This urinary concentration is not suitable as a biological exposure index because of its non-linearity.

\section{Discussion \\ CHARACTERISTICS OF THE PRESENT PHYSIOLOGICALLY BASED PHARMACOKINETIC MODEL}

Various physiologically based pharmacokinetic models are used in general to describe uptake, distribution, metabolism, and elimination of organic solvents in the human body.$^{1-8}$ Most of these models do not take into account the absorption of solvents in the mucous layer of the respiratory tract, although the absorption greatly affects the kinetic behaviour of water soluble solvents. The present physiologically based pharmacokinetic model includes two compartments, the mucous layers of the inhaled and exhaled air tracts, to take this absorption into account. Comparison of the simulated result with the experimental data showed that volume of the mucous layer and the respiration rates play important parts in the appropriate simulation (fig 4). Respiration rate should be around $14 \mathrm{~min}^{-1}$ at rest and around $18 \mathrm{~min}^{-1}$ at $50 \mathrm{~W}$ according to normal respiratory rates. ${ }^{1320}$ The best fits in the three simulations resulted from volumes of the mucous layer of $0.6,2.0$, and $1.0 \mathrm{ml}$, respectively, for series $1,2 \mathrm{a}$, and 3 . Even if the volume of the mucous layer is set at $1.0 \mathrm{ml}$ for series 1 and $2 \mathrm{a}$, the relative errors of the simulation are less than $15 \%$ for acetone concentration in arterial blood-for example, at the end of exposure: observed value $=14.8 \mathrm{mg} / 1 \quad v$ simulated result $=13.7$ $\mathrm{mg} / \mathrm{l}$ in series 1 , observed value $=16.9 \mathrm{mg} / 1 v$ simulated result $=19 \cdot 2 \mathrm{mg} / 1$ in series $2 \mathrm{a}$-and less than $15 \%$ for acetone concentration in end exhaled air-for example, at the end of exposure: observed value $=212 \mathrm{ppm} v$ simulated result $=235 \mathrm{ppm}$ in series 1 , observed value $=108 \mathrm{ppm} v$ simulated result $=96$ ppm in series $2 \mathrm{a}$. As these degrees of error are tolerable for simulation, the volume of mucous layer can be set at about $1.0 \mathrm{ml}$.

Because the total wall area of the air tract is about $5000 \mathrm{~cm}^{2}, 13$ the outermost mucous layer corresponding to the mucous layer of the inhaled and exhaled air tracts in our model is around $2 \mu \mathrm{m}$ thick with a volume of mucous layer of $1.0 \mathrm{ml}$. In reality, the mucous layer lining the wall is $5-10 \mu \mathrm{m}$ thick. ${ }^{13}$ As stated in the section on methods, this physiologically based pharmacokinetic model does not take into consideration the deeper mucous layer based on the assumption that the instantaneous equilibrium of acetone between the outermost layer and air can be achieved but that between the deeper portion and air cannot. An anatomical boundary line does not exist between the outermost layer and the deeper portion. It would be the mean depth of the mucous layer where the instantaneous equilibrium with air can be achieved. To make this physiologically based pharmacokinetic model general, a physical explanation based on the diffusion rate of acetone in mucus is necessary.

Although instantaneous equilibrium between the deeper mucous layer and air may not be achieved, acetone absorbed in the outermost mucous layer must slowly diffuse partly to the deeper mucous layer and the wall of the air tract during exposure. Consequently, some of the acetone absorbed in the wall may enter the bloodstream. Animal studies have shown that acetone absorbed in nasal tissue can be removed by the nasal bloodstream. ${ }^{26}$ Nasal tissue possesses a xenobiotic metabolising potential, ${ }^{26} 27$ so that the acetone taken into it may be partly metabolised. The nasal metabolic clearance and the uptake by the nasal bloodstream may be very small compared with hepatic clearance and uptake through the lung. ${ }^{2627}$ Consequently, these factors were not included in our model.

Our model also does not take into account the respiratory dead space. In the actual situation, acetone vapour that reaches the dead space, but not the alveoli, must be partly added to the outer mucous layer. If the added acetone is released during exhalation, the acetone concentration in the end exhaled air may be slightly higher than that in our simulation.

The hepatic clearance of acetone in humans was estimated by extrapolating the data for rats. Such extrapolation may be highly misleading, but adjustments of the volume of the mucous layer until a good fit to the data is obtained can mask an inappropriate value for hepatic clearance. For example, although an overestimated hepatic clearance might lead to a lower acetone concentration in arterial blood, use of a smaller volume of the mucous layer can seemingly correct this result (fig 4). But such a smaller volume can also lower the acetone concentration in end exhaled air (fig 4). In our study, both the 
simulated acetone concentration in arterial blood and that in end exhaled air agreed well with the corresponding observed values. Consequently, the estimated hepatic clearance should not differ greatly from the true value, although it is necessary to evaluate to what extent the model is sensitive to change in clearance.

\section{PREDICTED TIME COURSE OF ACETONE} CONCENTRATION IN THE HUMAN BODY

For fat soluble solvents like trichloroethylene, their kinetic behaviour in fatty tissue is predicted to differ greatly from those in the other tissues due to the high fat/blood partition coefficient and slow blood flow in fatty tissue. $^{34}$ But the simulated time course of acetone in fatty tissues was similar to those in the other tissues (fig 5). This result is considered to reflect the low fat/blood partition coefficient $(0 \cdot 44)$.

The concentration of acetone in end exhaled air was expected to rise very rapidly at the start of exposure and decrease at the end of exposure (fig 6). Such rapid change was confirmed by the experimental study of acetone (figs 2 and 3 ). This can be explained from the absorption and release of acetone by the mucous layer of the respiratory tract. The reason why the rapid change can be predicted by our physiologically based pharmacokinetic model is that this model includes the outermost layer of the mucus. It does not, however, take into consideration the deeper mucous layer and the wall structure. As stated above, part of the acetone absorbed in the outer mucous layer must slowly diffuse to the deeper portion during exposure, so that the deeper portion would have accumulated acetone at the end of exposure. Consequently, the rapid drop in the concentration of acetone in end exhaled air at the end of exposure may actually be slower than that in the simulation.

The simulation for a week predicted that acetone concentration in arterial blood before the shift would become constant on the fourth and fifth days in the first week even at the highest exposure (fig 7). This behaviour is different from that for fat soluble solvents. For example, chlorobenzene concentration before the shift is expected to become constant on the fourth and fifth days in the third week. ${ }^{28}$ This difference is caused by the vastly different fat/blood partition coefficients (chlorobenzene: $86,{ }^{28}$ acetone: $0 \cdot 44^{17}$ ), which make the fatty tissues an accumulator for chlorobenzene but not for acetone.

\section{BIOLOGICAL EXPOSURE INDICES}

The concentrations of acetone in the blood at the end of a shift and in the urine for the last two hours of the shift were predicted to be good biological exposure indices. The present simulation was based on the simple exposure scenario (constant exposure concentration and workload) and typical values of physiological variables. In actual workplaces, variation of exposure concentrations within the day, various intensities of workload, and varia- tions between workers in physiological values including hepatic and kidney functions exist, so that the relations between acetone exposure and the biological indices are affected by these variations. Nevertheless, the simulated relation for acetone concentration in the blood at the end of exposure agreed well with the regression line obtained in a field study by Fujino et al $^{29}$ (fig 8). Although it differed from the regression line of Mizunuma et $a^{30}$ (fig 8), this discrepancy cannot be attributed to any inadequacy of our model considering these stated differences between the simulated situation and the actual one. The simulated line for urinary acetone concentrations in the last two hours of the shift agreed well with the regression line obtained by Mizunuma et $a l^{30}$ but differed from the regression line of Fujino et $a^{29}$ (fig 10). The same considerations that apply to the blood can also apply to urine. It is not clear why the simulated results fit the observed data of Mizunuma et al well for urine but not for blood, but the opposite is true for the observed data of Fujino et al.

The concentration of acetone in exhaled alveolar air was expected to be a good biological exposure index in this simulation, but it is difficult to collect the true air exhaled from the alveoli due to the absorption of acetone by the mucous layer. The concentration of acetone in end exhaled air one minute after exposure was also expected to be a good biological exposure index, and in reality it can be easily collected. Our simulation was conducted, however, on the basis that humans breathe regularly. In general, exhaled air is collected by forced exhalation. The effect of acetone absorption by the mucous layer on the acetone concentration in exhaled air may be lower in forced exhalation than in regular exhalation because the volume of air exhaled from the alveoli becomes much larger, which lowers the effect of the absorption in the mucous layer. Thus the value for forced exhalation can be expected to be between the simulated concentration of exhaled alveolar air and that of end exhaled air one minute after the end of exposure. The regression line obtained in a field study ${ }^{29}$ meets this consideration (fig 9).

\section{Conclusion}

We have shown that the simulated acetone concentrations in arterial blood, end exhaled air, fatty tissue, and urine agreed well with the experimental data. In the simulation of the occupational situation, the results fit the data from field studies tolerably well. Consequently, the present physiologically based pharmacokinetic model should be useful for understanding and explaining the kinetic behaviour of acetone in the human body. To make this model general, a physical explanation is needed for the appropriate volume of the mucous layer. Furthermore, it is also necessary to examine whether the model can be applied to other water soluble solvents like alcohols. 
We are grateful to Professor G Johanson, National Institute of Occupational Health, Solna, Sweden, and Professor A Sato, Yamanashi Medical College, Yamanashi, Japan, for their encouragement and instructive discussions.

1 Fiserova-Bergerova V, Vlach J, Singhal K. Simulation and prediction of uptake, distribution, and exhalation of organic solvents. Br f Ind Med 1974;31:45-52.

2 Ramsey JC, Andersen ME. A physiologically based description of the inhalation pharmacokinetics of styrene in rats and humans. Toxicol Appl Pharmacol 1984;73: 159-75

3 Droz PO, Guillemin MP. Human styrene exposure. (V) Development of a model for biological monitoring. Int Arch Occup Environ Health 1983;53:19-36.

4 Fernandez JG, Droz PO, Humbert BE, Caperos JR. Trichloroethylene exposure simulation of uptake, excretion, and metabolism using a mathematical model. $B r F$ Ind Med 1977;34:43-55.

5 Koizumi A. Potential of physiologically based pharmacokinetics to amalgamate kinetic data of trichloroethylene and tetrachloroethylene obtained in rats and man. $\mathrm{BrF}$ Ind Med 1989;46:239-49.

6 Endoh K, Kaneko T, Sato A. A physiologically based pharmacokinetic model to describe the transfer of organic solvents in a human body: simulation of kinetic behaviour of trichloroethylene using a spread sheet program. Fapanese fournal of Industrial Health 1989;31:348-54. (In Japanese with English abstract.)

7 Johanson G. Physiologically based pharmacokinetic modeling of inhaled 2-butoxyethanol in man. Toxicol Lett 1986;34:23-31.

8 Perbellini L, Mozzo P, Olivato D, Brugnone F. "Dynamic" Biological exposure indexes for $n$-hexane and 2,5-hexanedione, suggested by a physiologically based pharmacokinetic model. Am Ind Hyg Assoc $\mathcal{F}$ 1990;51:356-62.

9 Åstrand I. Effect of physical exercise on uptake, distribution and elimination of vapors in man. In: FiserovaBergerova V, ed. Modeling of inhalation exposure to vapors: Uptake, distribution, and elimination. Vol 2. Boca Raton: CRC Press, 1983:107-30.

10 Dahl AR, Snipes MB, Gerde P. Sites for uptake of inhaled vapors in beagle dogs. Toxicol Appl Pharmacol 1991;109: 263-75

11 Gerde P, Dahl AR. A model for the uptake of inhaled vapors in the nose of the dog during cyclic breathing Toxicol Appl Pharmacol 1991;109:276-88.

12 Morris JB, Hassett DN, Blanchard KT. A physiologically based pharmacokinetic model for nasal uptake and metabolism of nonreactive vapors. Toxicol Appl Pharmacol 1993;123:120-9.

13 Johanson $G$. Modelling of respiratory exchange of polar solvents. Ann Occup Hyg 1991;35:323-39.
14 Fiserova-Bergerova V, Hughes HC. Species differences in bioavailability of inhaled vapors and gases. In: FiserovaBergerova V, ed. Modeling of inhalation exposure to vapors: Uptake, distribution, and elimination. Vol 2. Boca Raton: CRC Press, 1983:97-106.

15 Sato A, Nakajima T. Partition coefficients of some aromatic hydrocarbons and ketones in water, blood and aromatic hydrocarbons and keton
oil. Br F Ind Med 1979;36:231-4.

16 Wigaeus E, Holm S, Astrand I. Exposure to acetone: uptake and elimination in man. Scand $\mathcal{f}$ Work Enviro Health 1981;7:84-94.

17 Fiserova-Bergerova V, Diaz ML. Determination and prediction of tissue-gas partition coefficients. Int Arch Occup Environ Health 1986;58:75-87.

18 Adolph EF. Quantitative relations in the physiological constitutions of mammals. Science 1949;109:579-85.

19 Stahl WR. Scaling of respiratory variables in mammals. f Appl Physiol 1967;22:453-60.

20 Hartley LH, Grimby G, Kilbom A, Nilsson NJ, Åstrand I, Bjure J, et al. Physical training in sedentary middle-aged and older men. III. Cardiac output and gas exchange at submaximal and maximal exercise. Scand $f$ Clin Lab Invest 1969;24:335-44.

21 Hallier E, Filser JG, Bolt HM. Inhalation pharmacokinetics based on gas uptake studies. Arch Toxicol 1981;47: 293-304.

22 Price TD, Rittenberg D. The metabolism of acetone: gross aspects of catabolism and excretion. F Biol Chem 1950; 185:449-59.

23 Yamaoka K. Pharmacokinetic evaluation using micro computer. Kyoto: Nankodo, 1984:63-9. (In Japanese.)

24 Wigaeus E, Lof A, Nordqvist MB. Uptake, distribution, metabolism, and elimination of styrene in man: a comparison between single exposure and co-exposure with acetone. Br 7 Ind Med 1984;41:539-46.

25 American Conference of Governmental Industrial Hygienists. Documentation of the threshold limit values and biological exposure indices. 6th ed Vol I Cincinnati: ACGIH, 1991:271-4.

26 Morris JB, Cavanagh DG. Deposition of ethanol and acetone vapors in the upper respiratory tract of the rat. Fundam Appl Toxicol 1986;6:78-88.

27 Morris JB, Cavanagh DG. Metabolism and deposition of propanol and acetone vapors in the upper respiratory tract of the hamster. Fundam Appl Toxicol 1987;9:34-40.

28 Kumagai S, Matsunaga I. Effect of variation of exposure to airborne chlorobenzene on internal exposure and concentrations of urinary metabolite. Occup Environ Med 1995;52:65-70

29 Fujino A, Satoh T, Takebayashi T, Nakashima H, Sakurai $\mathrm{H}$, Higashi $\mathrm{T}$, et al. Biological monitoring of workers exposed to acetone in acetate fibre plants. Br 7 Ind Med 1992;49:654-7.

30 Mizunuma $K$, Yasugi $T$, Kawai T, Horiguchi $S$, Ikeda $M$ Exposure-excretion relationship of styrene and acetone in factory workers: a comparison of a lipophilic solven and a hydrophilic solvent. Arch Environ Contam Toxicol 1993;25:129-33 